\title{
Erratum to: Emotion Recognition: A Step Ahead of Traditional Approaches
}

Surbhi Agarwal, Madhulika Bhatia and Madhurima Hooda

Erratum to:

Chapter "Emotion Recognition: A Step Ahead of Traditional Approaches" in: S.C. Satapathy et al. (eds.), Information Systems Design and Intelligent Applications, Advances in Intelligent Systems and Computing 434, https://doi.org/10.1007/978-81-322-2752-6_71

In the original version of the book, the incorrectly published author name "Madhulika Madhurima" has been now corrected to read as "Madhulika Bhatia" and "Madhurima Hooda" in the chapter "Emotion Recognition: A Step Ahead of Traditional Approaches".

The updated online version for this chapter can be found at https://doi.org/10.1007/978-81-322-2752-6_71 